\title{
Children's International Polyposis (CHIP) study: a randomized, double-blind, placebo-controlled study of celecoxib in children with familial adenomatous polyposis
}

\author{
This article was published in the following Dove Press journal: \\ Clinical and Experimental Gastroenterology \\ 19 July 2017 \\ Number of times this article has been viewed
}

\author{
Carol A Burke' \\ Robin Phillips ${ }^{2}$ \\ Manuela F Berger ${ }^{3}$ \\ Chunming $\mathrm{Li}^{3}$ \\ Margaret Noyes Essex ${ }^{4}$ \\ Dinu lorga ${ }^{3}$ \\ Patrick M Lynch ${ }^{5}$ \\ 'Department of Gastroenterology \\ and Hepatology, Cleveland Clinic, \\ Cleveland, OH, USA; ${ }^{2}$ Department \\ of Surgery, St Mark's Hospital and \\ Academic Institute, Middlesex, UK; \\ ${ }^{3} \mathrm{Global}$ Clinical Affairs, ${ }^{4} \mathrm{Global}$ \\ Medical Affairs, Pfizer Inc., New York, \\ NY, ${ }^{5}$ Department of Gastroenterology, \\ Hepatology and Nutrition, The \\ University of Texas MD Anderson \\ Cancer Center, Houston, TX, USA
}

Correspondence: Carol A Burke Department of Gastroenterology and Hepatology, Cleveland Clinic, Desk A 31, 9500 Euclid Avenue, Cleveland, $\mathrm{OH}$ 44195, USA

Tel + I 2164446864

Fax + I 2164446305

Email burkecl@ccf.org
Objective: To evaluate the efficacy and safety of celecoxib versus placebo in the prevention and treatment of colorectal polyposis in children with familial adenomatous polyposis (FAP). Methods: In this Phase III, double-blind, randomized, placebo-controlled, multicenter trial patients aged 10-17 years with FAP were randomized to celecoxib (16 mg/kg/day) or placebo for up to 5 years. Patients underwent annual assessments, including colonoscopies, to detect the time from randomization to the earliest occurrence of $\geq 20$ polyps ( $>2 \mathrm{~mm}$ in size) or colorectal malignancy. The study was terminated early due to low rate of observed endpoints combined with a lower than expected enrollment rate. Descriptive results are provided.

Results: Of 106 randomized patients, 55 were treated with celecoxib (mean age 12.6 years; $52.7 \%$ female) and 51 were given placebo (mean age 12.2 years; $54.9 \%$ female). Disease progression ( $\geq 20$ polyps, $>2 \mathrm{~mm}$ in size) was observed in seven $(12.7 \%)$ and $13(25.5 \%)$ patients, respectively. The median time to disease progression was 2.1 years in the celecoxib group and 1.1 years for placebo. No patient developed colorectal cancer. The rate of adverse events (AEs) was similar in both groups ( $75.5 \%$ and $72.9 \%$, respectively). Three patients in the celecoxib group (none in the placebo group) experienced serious AEs.

Conclusion: In children with FAP, celecoxib was a well-tolerated treatment that was associated with a lower rate of colorectal polyposis and a longer time to disease progression compared with placebo. Due to the low rate of observed endpoints, the long-term impact of these results could not be ascertained.

Keywords: chemoprevention, clinical trial, adenoma, colorectal

\section{Introduction}

Familial adenomatous polyposis (FAP) is an autosomal dominant disease occurring in $\sim 1$ in 13,000 births. ${ }^{1}$ FAP is caused by a germline mutation in the adenomatous polyposis coli $(A P C)$ gene. A recent study reported that the mean age of onset of colorectal polyps in children with FAP was 13.4 years and $60 \%$ of children harbored $>50$ polyps at the time of diagnosis. ${ }^{2}$ If left untreated, polyposis invariably progresses, with a near certainty of patients developing colorectal cancer by the fifth decade of life if colectomy is not performed. ${ }^{3}$

The standard management of FAP is by surgical intervention and involves prophylactic total colectomy and ileorectal anastomosis (IRA), or proctocolectomy and ileal pouch anal anastomosis (IPAA) with postoperative endoscopic surveillance and polypectomy. Neither the timing of this surgery nor the procedure itself has been standardized 
in pediatric patients with FAP. ${ }^{4}$ Factors such as the presence of symptoms, polyp burden, psychosocial implications, and physical maturity, to name a few, must be considered before the decision to carry out this surgery is made.

Although surgery is effective in the prevention of colon cancer, it comes with a risk of mortality and postoperative complications. ${ }^{5,6}$ Moreover, surgery does not prevent the development of rectal or ileal pouch polyposis. In one longterm follow-up study, 7/34 (21\%) children treated with an IRA required proctectomy for either rectal cancer or advanced rectal polyposis, and 2/7 (29\%) FAP patients treated with IPAA had postoperative pouch polyposis within one decade of surgery. ${ }^{7}$ Another study in patients who had undergone IPAA for FAP 10 years previously found that $42 \%$ of patients had developed adenoma of the pouch. ${ }^{8}$

The use of chemoprevention for FAP has been reviewed previously. ${ }^{9}$ The goal of this therapy is to prevent, or lead to the regression of, colorectal adenomas and to prevent postoperative recurrence. If shown to be well tolerated and associated with long-term effectiveness in children, chemoprevention may delay the timing of, or alter the approach to, surgical intervention and may decrease the need for endoscopic intervention.

Following observations that gene expression of cyclooxygenase-2 (COX-2) is upregulated in many premalignant lesions such as colorectal adenomas, ${ }^{10,11} \mathrm{COX}-2$ selective inhibition has been considered as a potential chemopreventive strategy for treating FAP. A short-duration, randomized, placebo-controlled trial of celecoxib in children with FAP demonstrated a significant reduction in colorectal polyp burden compared with placebo; ${ }^{4}$ however, due to the short duration of that study, conclusions cannot be drawn on longterm efficacy and safety of celecoxib for FAP.

The objective of the present study was to assess the efficacy and safety of celecoxib versus placebo in children with FAP over a 5-year treatment duration.

\section{Methods}

\section{Trial design}

This was a Phase III, double-blind, randomized, placebocontrolled, multicenter trial in children with FAP. The study was designed to compare efficacy and safety of celecoxib versus placebo for the treatment of colorectal polyposis over a 5-year treatment period. The protocol and informed consent documents were reviewed and approved by an Institutional Review Board or Independent Ethics Committee at each participating study center (see the "Supplementary materials" and "Acknowledgments" sections), written assent was obtained from patients and written informed consent was obtained from parents prior to performing any study-related procedures. The trial was performed in accordance with the protocol, the International Conference on Harmonisation Good Clinical Practice guidelines, and applicable local regulatory requirements and laws.

The multinational clinical study was conducted at 18 centers located in 13 countries.

\section{Participants and interventions}

A total of 200 eligible patients with FAP from multiple international centers were to be randomly assigned in a $1: 1$ ratio to receive either celecoxib (up to $16 \mathrm{mg} / \mathrm{kg} /$ day) or matching placebo for up to 5 years. Celecoxib was administered based on patients' weight as follows: body weight $25.0-37.5 \mathrm{~kg}$, dosage $200 \mathrm{mg}$ BID; 37.6-50.0 kg, $300 \mathrm{mg}$ BID; >50.0 kg, $400 \mathrm{mg}$ BID. The dose was adjusted based on body weight at return visits according to the protocol.

A central Internet/telephone system was used to assign each patient a randomization number. Randomization was carried out in block size of 4 and was stratified by center, age ( $\geq 12$ vs $<12$ years), and FAP phenotype (negative vs positive).

The study comprised patients aged 10-17 years (inclusive). Patients were required to have either a deleterious $A P C$ gene mutation, based on central genetic testing, including a non-attenuated genotype or an attenuated genotype and a personal history of colorectal adenomas plus a first-degree relative with colectomy, colorectal cancer, or $>100$ adenomas by the age of 40; or if no gene mutation was detected in the family, a personal history of $>2$ adenomas and a parent with the FAP phenotype, as stated earlier. Patients were required to have $<20$ polyps of $>2 \mathrm{~mm}$ at baseline colonoscopy that had to be completely excised, to render the colon free of polyps $>2 \mathrm{~mm}$ in size before administration of study drug.

Other inclusion criteria were negative pregnancy test and willingness to use effective birth control among female patients, abstention from use of other non-steroidal anti-inflammatory drugs (NSAIDs), intact colon, and normal blood tests.

Key exclusion criteria were sensitivity to $\mathrm{COX}-2$ selective NSAIDs, recent use of NSAIDs or oral adrenocorticosteroid, the need for concurrent use of fluconazole or lithium, and active peptic ulcer.

All patients underwent baseline colonoscopy under anesthesia, according to standard local practice, with complete excision of all polyps $>2 \mathrm{~mm}$ in size in eligible patients. At a Month 6 visit, patients underwent physical and laboratory examination and safety monitoring. At annual visits, colonoscopies were performed to assess the number and size of colorectal polyps, with complete excision for all 
patients who developed $<20$ colorectal polyps $(>2 \mathrm{~mm}$ in size). Histologic assessment of biopsied polyps was collected if available. Telephone monitoring was carried out at least every 3 months.

\section{Study endpoints}

The primary endpoint was the time to disease progression, defined as the time from randomization to the earliest occurrence of the following events:

1. appearance of $\geq 20$ polyps ( $>2 \mathrm{~mm}$ in size) at any colonoscopy during the study;

2. diagnosis of colorectal malignancy.

Secondary endpoints included

1. the time from randomization to treatment failure, where treatment failure was defined as:

a. earliest occurrence of $\geq 20$ polyps ( $>2 \mathrm{~mm}$ in size) at colonoscopy,

b. colorectal malignancy, or

c. treatment-related dropout (insufficient clinical response, disease progression, death, adverse events [AEs], treatment-related laboratory abnormalities, patient no longer willing to participate in the study, and other reasons related to treatment);

2. the weighted total number of colorectal polyps ( $>2 \mathrm{~mm}$ in size) diagnosed over Years 1-5 cumulatively, which was calculated as the sum of polyps over the 5 years divided by the number of colonoscopies the patient had during the study;

3. the polyp burden, defined as the sum of the largest diameters of all polyps ( $>2 \mathrm{~mm}$ in size) detected at each colonoscopy over the 5 years, divided by the number of colonoscopies the patient had during the study.

Safety endpoints were based on investigator-reported AEs, serious adverse events (SAEs), laboratory measurements, and physical examinations. AEs were coded according to criteria from the Medical Dictionary for Regulatory Activities, version 16.1.

\section{Data analysis}

The sample size calculation for this study was originally based on the primary endpoint and the assumption that the hazard rates (HRs) for patients treated with placebo and celecoxib were 0.37942 and 0.24079 , respectively. A total of 152 events would have been needed to show that the celecoxib group was superior to the placebo group $(\mathrm{HR}=1.576)$ at a significance level of 0.05 and with $80 \%$ power. Interim efficacy analyses were planned at increments of $\sim 30$ primary endpoint events.

In November 2012, the Data Safety Monitoring Board recommended that the trial be stopped if the 6-month enrollment rate was $<10$ patients, if the pooled observed $\mathrm{HR}$ was $<0.16$ events/person-year, or if there were any safety concerns. The first two conditions were met and the trial was terminated on October 31, 2013.

Due to early study termination, only descriptive statistics were analyzed and presented. The interim analysis that was originally planned was not conducted.

Endpoints were assessed in the intent-to-treat (ITT) population, consisting of all patients who were randomized (with study drug assignment designated according to initial randomization), regardless of whether patients received any study drug or received a different drug from that to which they were randomized.

Safety was assessed in all patients who received at least one dose of study medication, with treatment assignments designated according to the actual study treatment received.

\section{Results}

\section{Patient disposition}

Patients were recruited between September 2006 and October 2013 from centers in Belgium, Czech Republic, Hong Kong, Hungary, Israel, Italy, Slovakia, South Africa, Spain, Sweden, Ukraine, the UK, and the US. Of 305 patients screened for eligibility, 106 were randomized into the study: 55 to the celecoxib group and 51 to the placebo group (ITT population, Figure 1). Of those randomized, 53 (96.4\%) patients received treatment with celecoxib and 48 (94.1\%) patients received placebo (safety population); 64 patients were from the US, 35 were from Europe, and 7 were from Hong Kong, Israel, and South Africa.

Out of the 106 randomized patients, 85 were still active in 2013, when the study was terminated. The other 21 patients were discontinued prior to 2013, as follows: 2 in 2009, 3 in 2010, 5 in 2011, and 11 in 2012. Discontinuations were considered related to study drug treatment (treatment failure or related $\mathrm{AE}$ resulting in discontinuation) occurred for nine $(16.4 \%)$ patients in the celecoxib group (three patients for AEs, six patients for treatment failure) and 11 (21.6\%) patients in the placebo group (all due to treatment failure). Compliance with medication, assessed by medication counts and patient diary, was similar between the groups. 


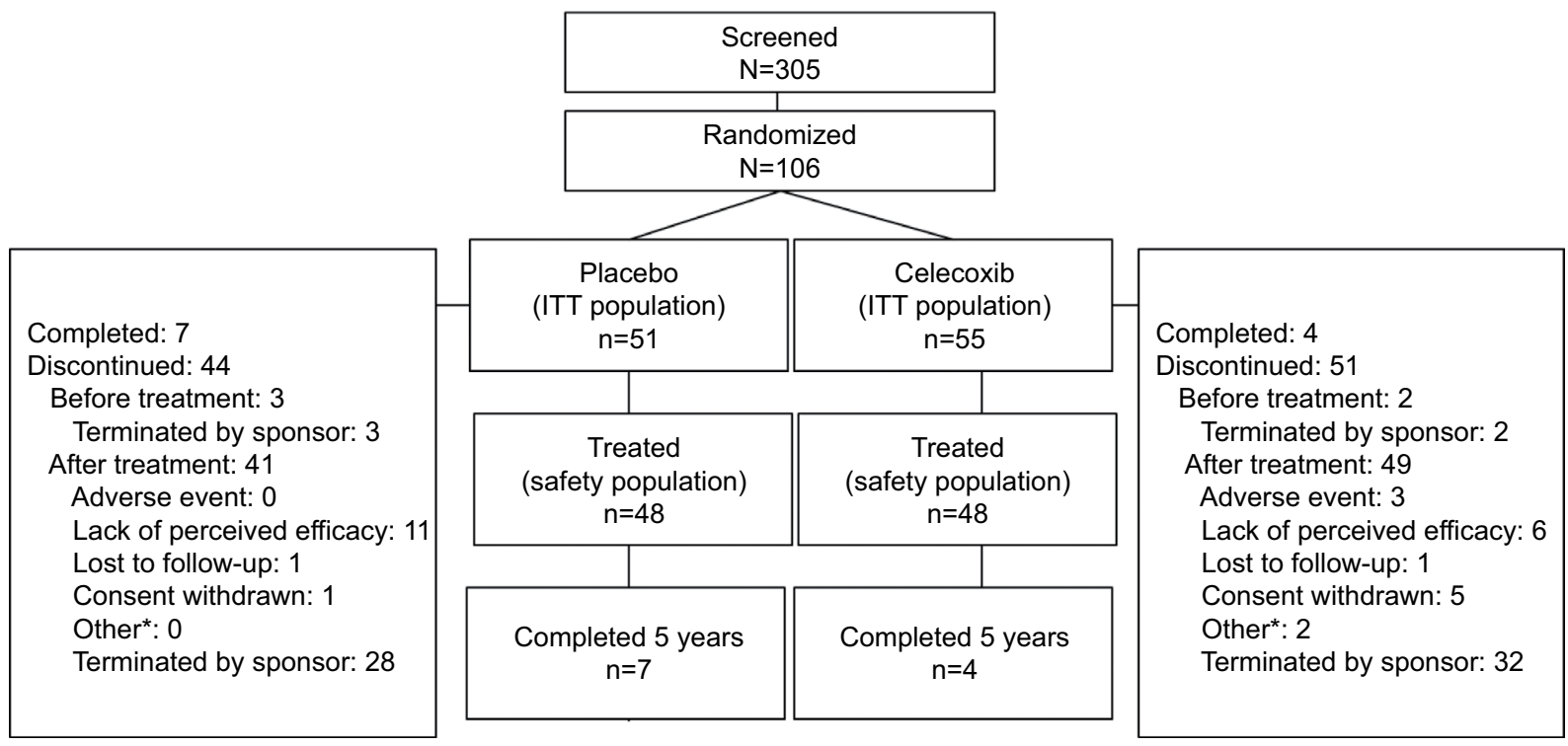

Figure I Patient disposition.

Note: *Includes "Does not meet entrance criteria" and "Protocol violation".

Abbreviation: ITT, intent-to-treat.

\section{Baseline characteristics}

The two arms of the study were balanced with respect to baseline characteristics; most patients were aged $\sim 12$ years and were white, and there were slightly more females than males in both groups (Table 1).

Ongoing coexisting medical conditions were reported in $37(67.3 \%)$ patients in the celecoxib group and $28(54.9 \%)$ in the placebo group. The most common of these were nervous system disorders (16 patients in the celecoxib group vs 15 in the placebo group), immune system disorders (13 vs 9 , respectively), and psychiatric disorders (11 vs 10 , respectively). The majority of patients' mutation location was exon $15(n=65)$, with equal numbers $(n=12)$ having mutations at exons 10-14 and exons 5-8, and fewer at exon $9(n=4)$ and exons $1-4(n=2)$. An additional 11 patients had other mutations.

\section{Study endpoints}

Among those who were treated (safety population), the median duration of treatment was 23.0 months for patients in the celecoxib group and 25.5 months for those in the placebo group. In the ITT population, 20 patients met the primary endpoint (development of $\geq 20$ polyps $>2 \mathrm{~mm}$ in size) during the study, seven (12.7\%) of 55 patients in the celecoxib group and 13 (25.5\%) of 51 in the placebo group. The median time to disease progression was 2.1 years in the celecoxib group and 1.1 years for placebo. None of the patients developed a colorectal malignancy. The cumulative rate of patients reaching the primary endpoint over the 5-year follow-up period (appearance of $\geq 20$ polyps that are $>2 \mathrm{~mm}$ in size) is shown in Figure 2.

A similar proportion of patients met the secondary endpoint (14 in each group), which compared the time from

Table I Baseline patient characteristics (ITT population)

\begin{tabular}{|c|c|c|c|c|c|c|}
\hline & \multicolumn{3}{|c|}{ Celecoxib $(n=55)$} & \multicolumn{3}{|c|}{ Placebo $(n=5 I)$} \\
\hline & Female & Male & Total & Female & Male & Total \\
\hline Sex, n (\%) & $29(52.7)$ & $26(47.3)$ & 55 & $28(54.9)$ & $23(45.1)$ & 51 \\
\hline \multicolumn{7}{|l|}{ Age } \\
\hline Mean (SD) & $12.4(2.3)$ & $12.8(2.0)$ & $12.6(2.2)$ & $12.0(1.7)$ & $12.4(2.0)$ & $12.2(1.8)$ \\
\hline Range & $10-17$ & $10-17$ & $10-17$ & $10-15$ & $10-17$ & $10-17$ \\
\hline \multicolumn{7}{|l|}{ Race, n (\%) } \\
\hline White & $26(89.7)$ & $20(76.9)$ & $46(83.6)$ & $21(75.0)$ & $19(82.6)$ & $40(78.4)$ \\
\hline Black & I (3.4) & I (3.8) & $2(3.6)$ & 0 & $2(8.7)$ & $2(3.9)$ \\
\hline Asian & 0 & I (3.8) & $\mathrm{I}(\mathrm{I} .8)$ & 0 & I (4.3) & I (2.0) \\
\hline Other & $2(6.9)$ & $4(15.4)$ & $6(10.9)$ & $7(25.0)$ & I (4.3) & $8(\mid 5.7)$ \\
\hline
\end{tabular}

Abbreviations: ITT, intent-to-treat; SD, standard deviation. 


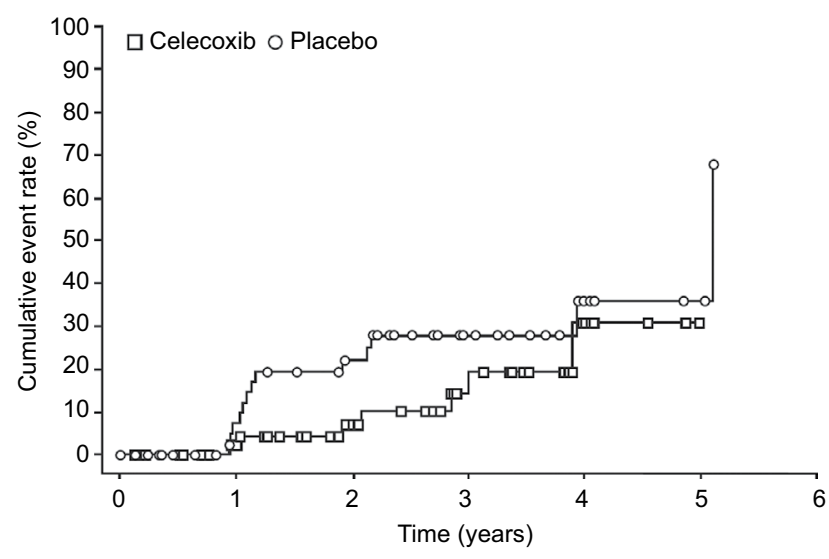

Figure 2 Time to disease progression (ITT population).

Note: Event defined as the appearance of $>20$ polyps that are $>2 \mathrm{~mm}$ in size or diagnosis of colorectal malignancy.

Abbreviation: ITT, intent-to-treat.

randomization to treatment failure (including development of $\geq 20$ polyps [ $>2 \mathrm{~mm}$ in size], diagnosis of colorectal malignancy, and treatment-related dropout). The median time to treatment failure was 2.0 years in the celecoxib group and 1.1 years for placebo. Treatment-related dropout occurred in $14(25.5 \%)$ patients in the celecoxib group and $12(23.5 \%)$ patients in the placebo group.

The weighted total number of colorectal polyps $(>2 \mathrm{~mm}$ in size) diagnosed over Years $1-5$ cumulatively is shown in Table 2. The mean (standard deviation) polyp burden in the celecoxib and placebo groups was 4.1 (1.68) and 4.3 (1.61) $\mathrm{mm}$, respectively.

\section{Safety}

The number of AEs and treatment-related AEs were similar in the two treatment groups (Table 3). Of the six patients in the celecoxib group who discontinued treatment due to AEs, three were considered to have had treatment-related AEs. The most common AEs, occurring in $>10 \%$ patients in a group, were headache, abdominal pain, vomiting, and nausea (Table 4).

Three patients in the celecoxib group experienced SAEs during the treatment period (depression, pneumonia, and periorbital cellulitis secondary to sinusitis); none were considered to be related to the study drug. No patients in the placebo group experienced SAEs. One patient in the celecoxib treatment group reported SAEs after completion of treatment that were considered by the investigator and sponsor as related to the study drug treatment. These were Escherichia sepsis, maternal exposure, and delivery of a premature baby. Despite taking oral contraceptives, this patient became pregnant during the study and gave birth, prematurely, $\sim 9$ months after study visit 3 (Year 1). Treatment with the study drug had
Table 2 Total number of colorectal polyps ( $>2 \mathrm{~mm}$ in size) detected at annual colonoscopies findings (ITT population)

\begin{tabular}{|c|c|c|}
\hline & $\begin{array}{l}\text { Celecoxib } \\
(n=55)\end{array}$ & $\begin{array}{l}\text { Placebo } \\
(n=51)\end{array}$ \\
\hline \multicolumn{3}{|l|}{ Year I } \\
\hline $\mathrm{N}$ & 27 & 30 \\
\hline Mean (SD) & $3.0(2.68)$ & $8.1(7.32)$ \\
\hline Median & 2.0 & 6.0 \\
\hline \multicolumn{3}{|l|}{ Year 2} \\
\hline $\mathrm{N}$ & 21 & 25 \\
\hline Mean (SD) & $8.8(6.63)$ & I $3.7(10.5 \mid)$ \\
\hline Median & 6.0 & 11.0 \\
\hline \multicolumn{3}{|l|}{ Year 3} \\
\hline $\mathrm{N}$ & 16 & 14 \\
\hline Mean (SD) & $13.4(\mid 1.31)$ & $22.3(11.74)$ \\
\hline Median & 10.0 & 20.0 \\
\hline \multicolumn{3}{|l|}{ Year 4} \\
\hline $\mathrm{N}$ & 8 & 7 \\
\hline Mean (SD) & $18.6(17.65)$ & $36.4(22.50)$ \\
\hline Median & 11.5 & 32.0 \\
\hline \multicolumn{3}{|l|}{ Year 5} \\
\hline $\mathrm{N}$ & 2 & 2 \\
\hline Mean (SD) & $30.5(21.92)$ & $46.5(34.65)$ \\
\hline Median & 30.5 & 46.5 \\
\hline \multicolumn{3}{|c|}{ Years I-5 cumulatively } \\
\hline $\mathrm{N}$ & 33 & 36 \\
\hline Mean (SD) & $4.3(3.58)$ & $8.6(7.12)$ \\
\hline Median & 3.0 & 7.0 \\
\hline
\end{tabular}

Abbreviations: ITT, intent-to-treat; SD, standard deviation.

been discontinued $\sim 1$ month previously. The infant died 11 days later.

The incidence of specific laboratory abnormalities and shifts of baseline values from normal levels was comparable between the treatment groups.

\section{Discussion}

This Phase III randomized, double-blind, placebo-controlled celecoxib trial is one of the largest studies to assess the efficacy and safety of chemoprevention in children with FAP. The study endpoint, progression of polyposis to $\geq 20$ polyps $>2 \mathrm{~mm}$ in size in 1 year, was determined to be of clinical significance and of prudent safety by a consensus of investigators before the study was incepted. Fewer children with FAP who received $16 \mathrm{mg} / \mathrm{kg} /$ day doses of celecoxib reached the primary endpoint than patients who received placebo. Furthermore, celecoxib was associated with a slower rate of disease progression compared with placebo, with the time to disease progression being on average 1 year longer for patients who received celecoxib than those who received placebo. No patients in either group developed colorectal cancer during the study and celecoxib was generally well tolerated. However, the long-term impact of celecoxib on colorectal 
Table 3 Patients with AEs (safety population)*

\begin{tabular}{|c|c|c|c|c|}
\hline & \multicolumn{2}{|c|}{ Celecoxib, $n(\%)(n=53)$} & \multicolumn{2}{|c|}{ Placebo, n (\%) $(n=48)$} \\
\hline & All causes & Treatment related & All causes & Treatment related \\
\hline Total AEs observed & 270 & 43 & 226 & 43 \\
\hline Patients with any $A E$ & $40(75.5)$ & $18(34.0)$ & $35(72.9)$ & $15(31.3)$ \\
\hline Patients with serious $A E s$ & $3(5.7)$ & 0 & 0 & 0 \\
\hline Patients with severe AEs & $5(9.4)$ & I (I.9) & $3(6.3)$ & 0 \\
\hline Patients permanently discontinued study due to AEs & $3(5.7)$ & 0 & 0 & 0 \\
\hline Patients permanently discontinued treatment due to AEs & $6(11.3)$ & $4(7.5)$ & I (2.I) & I (2.I) \\
\hline $\begin{array}{l}\text { Patients with dose reduction or temporary discontinuation } \\
\text { due to AEs }\end{array}$ & $19(35.8)$ & $4(7.5)$ & $12(25.0)$ & $2(4.2)$ \\
\hline
\end{tabular}

Notes: *Includes data up to 30 days after last dose of study drug. Except for the number of AEs, patients were counted only once per treatment in each row. Relationship of SAEs is displayed according to the investigator's assessment.

Abbreviations: $\mathrm{AE}$, adverse event; $\mathrm{SAE}$, serious adverse event.

Table 4 AEs occurring in $\geq 10 \%$ of patients per group (safety population)

\begin{tabular}{lll}
\hline & $\begin{array}{l}\text { Celecoxib, } \mathbf{n}(\%) \\
(\mathbf{n}=53)\end{array}$ & $\begin{array}{l}\text { Placebo, } \mathbf{n}(\%) \\
(\mathbf{n}=\mathbf{4 8})\end{array}$ \\
\hline Headache & $16(30.2)$ & $14(29.2)$ \\
Abdominal pain & $9(17.0)$ & $10(20.8)$ \\
Vomiting & $9(17.0)$ & $9(18.8)$ \\
Nausea & $8(15.1)$ & $8(16.7)$ \\
Cough & $8(15.1)$ & $6(12.5)$ \\
Abdominal discomfort & $9(17.0)$ & $4(8.3)$ \\
Oropharyngeal pain & $6(11.3)$ & $5(10.4)$ \\
Diarrhea & $6(11.3)$ & $4(8.3)$ \\
Fatigue & $6(11.3)$ & $4(8.3)$ \\
Nasopharyngitis & $6(11.3)$ & $4(8.3)$ \\
Upper respiratory tract infection & $4(7.5)$ & $9(18.8)$ \\
Influenza & $6(11.3)$ & $1(2.1)$ \\
Seasonal allergy & $2(3.8)$ & $5(10.4)$
\end{tabular}

Abbreviation: AEs, adverse events.

polyposis in children with FAP is unknown, because the study was terminated early due to the low occurrence of disease progression observed over the course of the study.

The results of this study, while limited by early termination, are valuable to clinicians and patients. Delaying disease progression in FAP is important as it affords a potential opportunity for children and parents to delay the timing for colectomy. Elective surgery is usually undertaken at an age of 16-20 years $;{ }^{12}$ however, the optimal timing has not been determined. ${ }^{4}$ Decisions about the timing of surgery should take into account psychosocial factors so as to minimize disruption to the child's personal development. In some cases, delaying surgery so that it causes the least disruption to educational or work activities is necessary. ${ }^{12}$ After IPAA, there is usually a permanent effect on the patient's bowel function, and in some cases sexual function can be altered. ${ }^{3}$ It is therefore important that patients are educated in advance about the possible quality of life changes post-surgery so that their expectations can be managed. ${ }^{3}$

Although the use of COX-2 selective and nonselective NSAIDs as potential adjunctive therapies for patients with
FAP who have undergone prophylactic surgery has been recommended, ${ }^{13}$ the application of these treatments in a pediatric population has not been rigorously tested. The Children's International Polyposis (CHIP) trial was designed to provide long-term efficacy and safety data on celecoxib for the reduction of the number of polyps in children with FAP. The ages of patients in this trial were representative of the age at which screening is carried out in children with polyposis. ${ }^{14}$ The study of chemoprevention in children with FAP is important for clinical practice, where early intervention may lead to slower progression of polyposis, which may translate to improved outcomes such as a delay in surgery or fewer polypectomies. Earlier studies of chemoprevention in FAP with NSAIDs focused predominantly on adult populations ${ }^{15-18}$ and found them to be useful adjuncts to endoscopy.

Previous trials ${ }^{4,15}$ and cohort studies ${ }^{19}$ have provided some evidence for the efficacy of celecoxib in FAP, but they were limited by both small sample size and relatively short duration. In a Phase I dose-escalation study in 18 children, three cohorts of patients received celecoxib at sequential doses of 4,8 , or $16 \mathrm{mg} / \mathrm{kg} /$ day, or placebo for 3 months. The number of polyps increased in the placebo and $4 \mathrm{mg} / \mathrm{kg}$ celecoxib groups by a median (range) of 17.5 ( -5 to 63 ) and 5.5 (2-17) polyps, respectively. In patients treated with celecoxib at 8 and $16 \mathrm{mg} / \mathrm{kg}$ doses, there was a median decrease in the number of polyps by -7.0 ( -2 to -16$)$ and -17.5 ( -2 to -48 ), respectively ( $p=0.011)$, confirming a dose-dependent response with celecoxib in FAP. ${ }^{4}$

The chemopreventive attributes of celecoxib have also been evaluated in a short-term study of adults. ${ }^{15}$ In this trial, a 6-month treatment period was selected, based on previous studies with sulindac, an NSAID that acts on both COX-1 and COX-2 enzymes and has also been shown to reduce the number and size of colorectal polyps. ${ }^{16,17}$ In total, 77 patients with FAP received $400 \mathrm{mg}$ celecoxib twice daily or placebo. In the active treatment group, there was a significant $28 \%$ 
reduction in the mean number of colorectal polyps ( $p=0.003)$ and a $31 \%$ reduction in polyp burden $(p=0.001)$, compared with placebo. ${ }^{15}$

Although NSAIDs are very commonly used drugs, longterm use at relatively high doses has been associated with increases in gastrointestinal and cardiovascular risk..$^{20}$ As a result, there is a need to assess the relative long-term risks and benefits of celecoxib in different clinical settings, including patients with or without vascular disease and in those with adenomas $;{ }^{21}$ few studies have investigated the long-term effects of NSAIDs in children. The Adenoma Prevention with Celecoxib trial examined the efficacy and safety of celecoxib for preventing sporadic colorectal adenoma in $>2,000$ adults who were at high risk for colorectal cancer. Celecoxib was an effective agent in the trial but could not be recommended because of potential cardiovascular AEs. ${ }^{18} \mathrm{~A}$ 5-year follow-up of the trial noted that cardiovascular AEs were particularly associated with a history of atherosclerotic heart disease..$^{22}$ It is not clear whether there are specific populations who may benefit from adenoma prevention with a COX-2 selective NSAID.

Because FAP is incurable and associated with substantial morbidity and tumor-related mortality, a safe and effective agent to manage the disease is desperately needed. Understanding of the utility of chemoprevention in the colorectum of patients with FAP has progressed over the last 40 years, due to several studies that have shown a short-term benefit of NSAIDs on polyp burden. ${ }^{4,5-17}$ Despite this, the search continues for a chemopreventive agent that is both effective and nontoxic. This study, despite being terminated prematurely, determined that at a median of 2 years of treatment there was a $50 \%$ reduction in the number of pediatric patients who met the primary outcome of disease progression in the celecoxib arm compared with patients in the placebo arm. Although it was not possible to confirm the statistical significance of celecoxib's efficacy, the safety results indicate that celecoxib was a well-tolerated treatment in this population of children with FAP.

\section{Acknowledgments}

The study was sponsored by Pfizer. Editorial support was provided by K Bradford of PAREXEL and Joshua Fink of Engage Scientific Solutions and was funded by Pfizer. The authors gratefully acknowledge the study site investigators Belgium: Prof Etienne Sokal, Cliniques Universitaires SaintLuc/Pediatrie Generale, Brussels; Prof Catharina Dhooge and Dr Peeters Marc, Universitair Ziekenhuis Gent/Pediatrische Hematologie-Oncologie en Stamceltransplantatie, Ghent; Czech Republic: Dr Jiri Nevoral, Fakultni Nemocnice
Motol, Prague; Hong Kong: Prof Simon Siu-Man Ng, The Chinese University of Hong Kong; Dr Judy Ho, Queen Mary Hospital; Hungary: Dr Tunde Kristof, Endomedix Diagnosztikai Kozpont-Miskolc; Israel: Prof Ron Shaoul, Meyer Children's Hospital, Haifa; Prof Raanan Shamir, Schneider Children's Medical Center of Israel, Petah Tikva; Dr Avi On, The Baruch Padeh Medical Center, Poriya; Dr Shlomi Cohen, Dana Children's Hospital, Tel Aviv; Italy: Dr Vittoria Stigliano, Polo Oncologico Istituto Regina Elena, Rome; Dr Giorgio Frosini, Policlinico Le Scotte, Siena; Puerto Rico: Dr Marcia Cruz-Correa, Puerto Rico Clinical and Translational Research, Rio Piedras; Slovakia: Dr Iveta Cierna, Detska Klinika, Bratislava; South Africa: Dr Paul A Goldberg, Groote Schuur Hospital, Cape Town; Spain: Dr Pedro Perez Segura, Hospital Clinico San Carlos, Madrid; Sweden: Dr Jan Bjork and Dr Rolf Hultcrantz, Karolinska University Hospital, Stockholm; Ukraine: Prof Ivan P Zhurylo, Regional Children's Clinical Hospital, Donetsk; UK: Dr Susan Katherine Clark, St Mark's Hospital, Middlesex; USA: Dr Patrick Michael Lynch, University of Texas, Houston, TX; Dr Jose Gaston Guillem, Memorial Sloan Kettering Cancer Center, New York, NY; Dr Carol Ann Burke and Dr James Church, Cleveland Clinic, Cleveland, OH; Dr Ruben Eloy Quiros-Tejeira and Dr Thomas Attard, University of Nebraska Medical Center, Omaha, NB; Dr William D Jackson, Primary Children's Medical Center, Salt Lake City, UT; Dr Timothy M Geiger and Dr Wise Paul, Vanderbilt University Medical Center, Nashville, TN; Dr Danielle Kim Turgeon and Dr Stephen Gruber, University of Michigan Health System, Ann Arbor, MI; Dr Marc Isadore Brand, Rush University Medical Center, Chicago, IL; Dr Ajay Kaul, Cincinnati Children's Hospital Medical Center, Cincinnati, OH.

\section{Disclosure}

PML has received research support and has served on steering committees for Pfizer. He has also served on external advisory panels and speakers bureau for Myriad Genetics. RP has received research support and has served on steering committees for Pfizer. $\mathrm{CAB}$ has served on steering committees for Pfizer and has received research support from Pfizer, Salix, and Cancer Prevention Pharmaceuticals. MB, CL, MNE, and DI are employees of, and hold stock and/or stock options in, Pfizer. ClinicalTrials.gov identifier: NCT00585312. The authors report no other conflicts of interest in this work.

\section{References}

1. Bisgaard ML, Fenger K, Bulow S, Niebuhr E, Mohr J. Familial adenomatous polyposis (FAP): frequency, penetrance, and mutation rate. Hum Mutat. 1994;3:121-125. 
2. Kennedy RD, Potter DD, Moir CR, El-Youssef M. The natural history of familial adenomatous polyposis syndrome: a 24 year review of a single center experience in screening, diagnosis, and outcomes. J Pediatr Surg. 2014;49:82-86.

3. Half E, Bercovich D, Rozen P. Familial adenomatous polyposis. Orphanet J Rare Dis. 2009;4:22.

4. Lynch PM, Ayers GD, Hawk E, et al. The safety and efficacy of celecoxib in children with familial adenomatous polyposis. Am J Gastroenterol. 2010;105:1437-1443.

5. Bulow C, Vasen H, Jarvinen H, Bjork J, Bisgaard ML, Bulow S. Ileorectal anastomosis is appropriate for a subset of patients with familial adenomatous polyposis. Gastroenterology. 2000;119:1454-1460.

6. Kirchhoff P, Clavien PA, Hahnloser D. Complications in colorectal surgery: risk factors and preventive strategies. Patient Saf Surg. 2010;4:5.

7. Booij KA, Mathus-Vliegen EM, Taminiau JA, et al. Evaluation of 28 years of surgical treatment of children and young adults with familial adenomatous polyposis. J Pediatr Surg. 2010;45:525-532.

8. Friederich P, de Jong AE, Mathus-Vliegen LM, et al. Risk of developing adenomas and carcinomas in the ileal pouch in patients with familial adenomatous polyposis. Clin Gastroenterol Hepatol. 2008;6: 1237-1242.

9. Kim B, Giardiello FM. Chemoprevention in familial adenomatous polyposis. Best Pract Res Clin Gastroenterol. 2011;25:607-622.

10. Eberhart CE, Coffey RJ, Radhika A, Giardiello FM, Ferrenbach S, DuBois RN. Up-regulation of cyclooxygenase 2 gene expression in human colorectal adenomas and adenocarcinomas. Gastroenterology. 1994;107:1183-1188.

11. Sinicrope FA, Lemoine M, Xi L, et al. Reduced expression of cyclooxygenase 2 proteins in hereditary nonpolyposis colorectal cancers relative to sporadic cancers. Gastroenterology. 1999;117:350-358.

12. Tudyka VN, Clark SK. Surgical treatment in familial adenomatous polyposis. Ann Gastroenterology. 2012;25:201-206.
13. Vasen HF, Moslein G, Alonso A, et al. Guidelines for the clinical management of familial adenomatous polyposis (FAP). Gut. 2008;57: 704-713.

14. National Comprehensive Cancer Network. Clinical practice guidelines in oncology. Genetic/familial high-risk assessment: colorectal version 2. 2014. Available from: nccn.org/professionals/physician_gls/f_guidelines.asp. Accessed July 25, 2014.

15. Steinbach G, Lynch PM, Phillips RK, et al. The effect of celecoxib, a cyclooxygenase-2 inhibitor, in familial adenomatous polyposis. $N$ Engl J Med. 2000;342:1946-1952.

16. Rigau J, Pique JM, Rubio E, Planas R, Tarrech JM, Bordas JM. Effects of long-term sulindac therapy on colonic polyposis. Ann Intern Med.1991;115: 952-954.

17. Giardiello FM, Hamilton SR, Krush AJ, et al. Treatment of colonic and rectal adenomas with sulindac in familial adenomatous polyposis. $N$ Engl J Med. 1993;328:1313-1316.

18. Bertagnolli MM, Eagle CJ, Zauber AG, et al. Celecoxib for the prevention of sporadic colorectal adenomas. $N$ Engl J Med. 2006;355: 873-884.

19. Huang K, Gutierrez LP, Bulow S, et al. Clinical characteristics and outcomes in familial adenomatous polyposis patients with a long-term treatment of celecoxib: a matched cohort study. Fam Cancer. 2011;10: 303-308.

20. Bhala N, Emberson J, Merhi A, et al. Vascular and upper gastrointestinal effects of non-steroidal anti-inflammatory drugs: meta-analyses of individual participant data from randomised trials. Lancet. 2013;382: 769-779.

21. Wang D, DuBois RN. The role of COX-2 in intestinal inflammation and colorectal cancer. Oncogene. 2010;29:781-788.

22. Bertagnolli MM, Eagle CJ, Zauber AG, et al. Five-year efficacy and safety analysis of the Adenoma Prevention with Celecoxib Trial. Cancer Prev Res (Phila). 2009;2:310-321. 


\section{Supplementary materials}

All Institutional Review Boards and Independent Ethics Committees for sites that screened patients are listed below:

- Cliniques Universitaires Commission d'Ethique Biomedicale Hospitalo- Facultaire, Bruxelles, Belgium

- Eticka komise pro Multicentricka klinicka hodnoceni Fakultni nemocnice v Motole, Praha, Czech Republic

- Joint Chinese University of Hong Kong.-New Territories East Cluster Clinical Research Ethics Committee. Prince of Whales Hospital, Shatin, Hong Kong

- Joint Chinese University of Hong Kong -New Territories East Cluster Clinical Research Ethics Committee. Prince of Whales Hospital, Shatin, Hong Kong

- Institutional Review Board of the University of Hong Kong/Hospital Authority Hong Kong West Cluster, Queen Mary Hospital, Hong Kong

- Egeszsegugyi Tudomanyos Tanacs Klinikai Farmakologiai Etikai Bizottsaga, Budapest, Hungary

- Rambam Medical Center Helsinki Committee, Haifa, Israel

- Helsinki Committee, Rabin Medical Center, Beilinson Campus, Petach Tikvah, Israel

- Baruch Padeh Medical Center, Poriya Helsinki Committee, Lower Galilee, Israel

- The Helsinki Committee Tel Aviv Sourasky Medical Center Sourasky MC, Tel Aviv, Israel

- Comitato Etico, Istituto Regina Elena, Roma, Italy

- Comitato Etico Locale per la Sperimentazione Clinica dei Medicinali, Siena, Italy

- Eticka komisia DFNsP BA, Detska fakultna nemocnica s poliklinikou, Bratislava. Slovakia

- University of Cape Town, Health Sciences Faculty, Research Ethics Committee, Cape Town, South Africa

- Hospital Clinico San Carlos Comite Etico de Investigacion Clinica Ciudad Universitaria, Madrid, Spain
- Regionala etikprovningsnamnden i Stockholm, Stockholm, Sweden

- Central Committee for Ethics Issues of Ministry of Health Care of Ukraine, Donetsk Regional Children Clinical Hospital, Local Ethics Committee, Donetsk, Ukraine

- Central London REC 1, Northwick Park Hospital, London, UK

- NRES Committee London, Health Research Authority National Research Ethics

- University of Texas MD Anderson Cancer Center, Houston, TX, USA

- Memorial Sloan Kettering Cancer Center Institutional Review Board, New York, NY, USA

- Case Western Reserve University School of Medicine, Cancer Institutional Review Board, Cleveland, OH, USA

- Institutional Review Board of the Cleveland Clinic, Cleveland, OH, USA

- University of Nebraska Medical Center Institutional Review Board, Omaha, NE, USA

- Children's Hospital Institutional Review Board, Omaha, NE, USA

- University of Utah Institutional Review Board, East Salt Lake City, UT, USA

- University of Utah Institutional Review Board, East Salt Lake City, UT, UA

- Vanderbilt University Institutional Review Board, South Nashville, TN, USA

- University of Michigan IRB-MED, Ann Arbor, MI, USA

- University of Michigan IRB-MED, Ann Arbor, MI, USA

- Rush University Medical Center, IRB Department, Chicago, IL, USA

- Cincinnati Children's Hospital Medical Center Institutional Review Board, Cincinnati, OH, USA

- Western Institutional Review Board, SW Olympia, WA, USA

- Human Research Subjects Protection Office (HRSPO) Office, UPR Medical Sciences Campus, San Juan, Puerto Rico
Clinical and Experimental Gastroenterology

\section{Publish your work in this journal}

Clinical and Experimental Gastroenterology is an international, peerreviewed, open access, online journal publishing original research, reports, editorials, reviews and commentaries on all aspects of gastroenterology in the clinic and laboratory. This journal is included on PubMed. The manuscript management system is completely online

\section{Dovepress}

and includes a very quick and fair peer-review system, which is all easy to use. Visit http://www.dovepress.com/testimonials.php to read real quotes from published authors. 